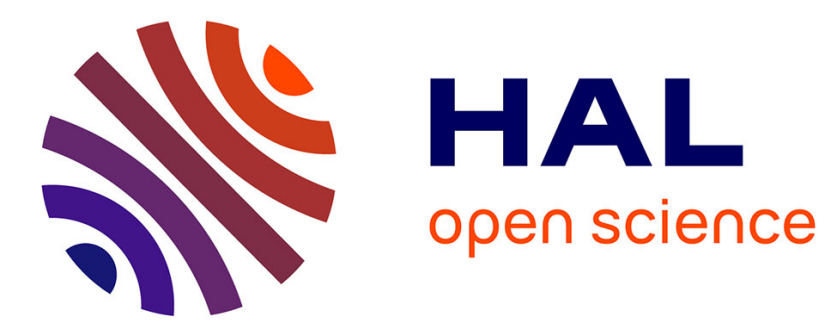

\title{
Mechanistic insights into Smiles rearrangement. Focus on $\pi-\pi$ stacking interactions along the radical cascade
}

\author{
Hassan Khartabil, Ludovic Doudet, Ingrid Allart-Simon, Miguel
}

Ponce-Vargas, Stéphane Gérard, Eric Hénon

\section{- To cite this version:}

Hassan Khartabil, Ludovic Doudet, Ingrid Allart-Simon, Miguel Ponce-Vargas, Stéphane Gérard, et al. Mechanistic insights into Smiles rearrangement. Focus on $\pi-\pi$ stacking interactions along the radical cascade. Organic \& Biomolecular Chemistry, 2020, 18 (35), pp.6840-6848. 10.1039/D0OB01511C . hal-03372250

\author{
HAL Id: hal-03372250 \\ https://hal.science/hal-03372250
}

Submitted on 10 Oct 2021

HAL is a multi-disciplinary open access archive for the deposit and dissemination of scientific research documents, whether they are published or not. The documents may come from teaching and research institutions in France or abroad, or from public or private research centers.
L'archive ouverte pluridisciplinaire HAL, est destinée au dépôt et à la diffusion de documents scientifiques de niveau recherche, publiés ou non, émanant des établissements d'enseignement et de recherche français ou étrangers, des laboratoires publics ou privés. 


\section{Mechanistic Insights into Smiles Rearrangement. Focus on $\pi-\pi$ Stacking Interactions along the Radical Cascade}

Received 00th January 20xx, Accepted 00th January 20xx

DOI: $10.1039 / x 0 \times x 00000 x$

\author{
Hassan Khartabil, ${ }^{a}$ Ludovic Doudet, ${ }^{a}$ Ingrid Allart-Simon, ${ }^{a}$ Miguel Ponce-Vargas, ${ }^{* a}$ Stéphane \\ Gérard*a $^{*}$ and Eric Hénon ${ }^{a}$
}

\section{Introduction}

The Smiles-type rearrangement refers to an intramolecular migration of a nucleophilic group on an aryl ring via an ipsosubstitution leading to functionalized arene and heteroarene molecules.1,2 It was originally developed in ionic series and was first transposed to radical chemistry by Speckamp for the transformation of $\alpha$-halopiperidine- $\mathrm{N}$-arylsulfonamides, ${ }^{3,4}$ growing significantly with discoveries in radical generation, thereby unlocking some original bond constructions. ${ }^{5,6}$ The desulfonylative-Smiles, in which the sulfur dioxide release drives the reaction forward has been a particularly rich area of exploitation. 7,8 This process is traditionally triggered by a free radical attack at the ipso position of sulfonates or sulfonamides followed by sulfur dioxide release and final hydrogen abstraction. ${ }^{9}$ Motherwell pointed out the importance of this approach, especially for the synthesis of biaryl systems. ${ }^{10-12}$ Despite its synthetic potential, only few reports of domino strategy involving this rearrangement are available in radical chemistry. ${ }^{13-16}$

As part of an ongoing research program dealing with the synthesis of complex indole-heterocycles by tandem reactions,

anstitut de Chimie Moléculaire de Reims UMR CNRS 7312, Université de Reims Champagne-Ardenne, Moulin de la Housse 51687, Reims Cedex 02 BP39 (France). *email:miguel.ponce-vargas@univ-reims.fr, stephane.gerard@univ-reims.fr Electronic Supplementary Information (ESI) available: [The conformers of all species considered in the studied reaction and their relative energies are available free of charge in the Electronic Supporting Information (ESI)]. See DOI: $10.1039 / x 0 \times x 00000 x$
Gerard and coworkers have recently described an unprecedented domino radical cyclisation-Smiles rearrangement affording 3-(2'-aryl-N-methyl acetamido) indolin-2-ones (Scheme 1 ), enabling the synthesis of new scaffolds of therapeutic interest. ${ }^{17}$

To the best of our knowledge, the theoretical mechanistic study of the radical version of the intramolecular radical Smiles rearrangement on an aromatic ring system bearing a sulfonamide-type linker has not yet been reported. The closest resembling reaction was addressed by Tentscher and coworkers, ${ }^{18}$ who conducted a theoretical study supported by laser flash photolysis experiments where the intramolecular nucleophilic attack of a pyrimidine nitrogen towards the ipso position of an aniline radical cation was examined. This reaction mechanism is similar to a closed-shell rearrangement preceding a sulfur dioxide release. Elsewhere, in a combined experimental and theoretical study, M. Feng and coworkers ${ }^{19}$ addressed the oxidation of sulfonamide antibiotics, where the two-electron ipso attack and the subsequent desulfonation take place in the same elementary step. Furthermore, Vasko and coworkers ${ }^{20}$ proposed a Smiles rearrangement reaction followed by cyclocondensation as a viable route to yield hybrid 1,4-thiazine1,2,3-dithiazolylium cations.

The aim of this study is to rationalize the experimental results obtained by Gerard and coworkers on the domino radical cyclisation-Smiles rearrangement (Scheme 1$)^{17}$ by means of theoretical methodologies. 


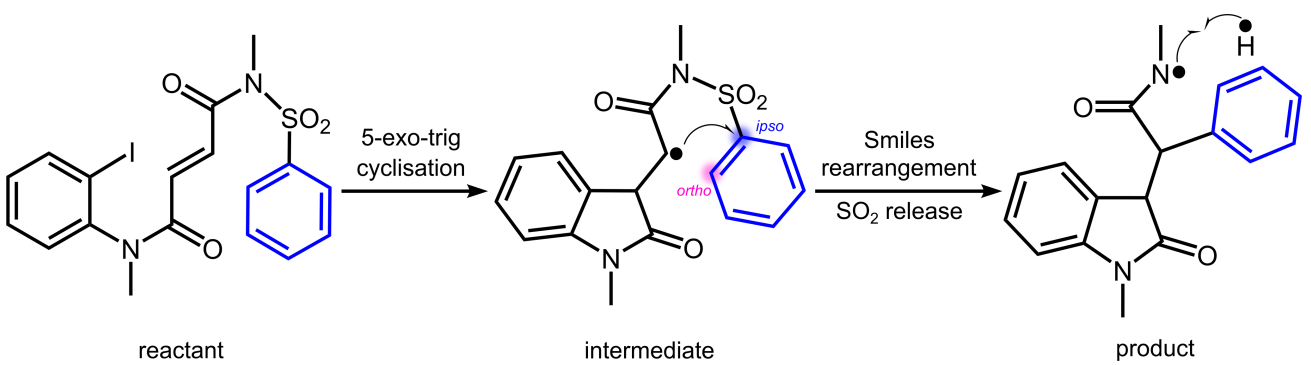

Scheme 1. A radical cyclisation-Smiles rearrangement affording 3-(2'-aryl-N-methyl acetamido) indolin-2-one. Experimental conditions: tris(trimethylsilyl)silane (TTMSS, $1.2 \mathrm{eq}$ ), 2,2'-azocyclohexanecarbonitrile (ACCN, 0.2 eq +0.2 eq), decane, $447 \mathrm{~K}, 3 \mathrm{~h} .{ }^{17}$

First, we provide a structural and energetic analysis of the species involved in the cascade reaction in $n$-decane. To complement this mechanistic study, analyses based on the Independent Gradient Model (IGM) ${ }^{21,22}$ have been performed to assess and depict critical non-covalent and covalent interactions along the reaction path. This recently introduced tool based on the topological analysis of the electron density can provide relevant insights, and serve as an interpretative technique of interactions occurring along this process. An attractive feature of this IGM- $\delta g$ approach is its automatic extraction workflow of interaction signatures, both in the covalent and non-covalent domains. In particular, it is properly designed to identify and quantify intramolecular weak interactions. $^{23}$

Theoretical results are compared with the available experimental data obtained by Gerard and coworkers. ${ }^{17}$ From this study, it appears that intramolecular $\pi-\pi$ stacking interactions play a key role in this domino radical cyclisationSmiles rearrangement. In addition, $\pi-\pi$ interaction plays a very important role in controlling reaction pathways, even in enantioselective reactions, such as in asymmetric catalysis. ${ }^{24,25}$ The present study establishes and validates the novel IGMbased computational tool for future mechanistic investigations conducted in a combined experimental and theoretical approach within a drug-design strategy, providing guidelines for the synthesis of new molecules through this uncommon radical cascade.

\section{Computational details}

All DFT (Density Functional Theory) calculations were performed within the unrestricted formalism by using the Gaussian16 software package. ${ }^{26}$ Energies and forces were computed with the M06-2X functional which includes dispersion corrections that reduce statistical errors in geometry optimizations. The DFT M06-2X functional has been chosen for reliable prediction of kinetics and thermochemistry, as shown in a recent radical reaction study. ${ }^{19} \mathrm{~A}$ polarizable continuum model of $n$-decane ${ }^{27-31}$ was employed to simulate experimental conditions. Geometry optimizations without symmetry constraints and the corresponding vibrational frequency calculations were conducted with the $6-311++G^{* *}$ basis set. Frequency calculations were performed to ensure the absence of imaginary frequencies for local minima and the presence of only one imaginary frequency for transition states. Reaction and activation free energies were obtained in the range 298-447 K by using the KiSThelP program. ${ }^{32}$ Rate constants were calculated with KiSThelP using the transition state theory (TST). Remarkably, the radical intermediate species (Scheme 1) exhibits an asymmetric carbon, and in the course of the reaction a second asymmetric carbon arises. Moreover, even up to three asymmetric carbons may appear in an alternative route (in species 3b described below). Thereby, all possible stereoisomers have be considered, and all the route possibilities have been carefully examined (Figure S1 in the ESI). The most favourable pathway is reported hereafter.

An analysis of non-covalent interaction was conducted by using the local IGM- $\delta g^{\text {inter }}$ descriptor 21,22 in order to clarify the role of intramolecular $\pi-\pi$ interactions between two fragments in the evolution of this cascade reaction. In addition, covalent bonding was also addressed by the IGM-IBSI methodology ( $\delta g^{\text {pair }}$ descriptor, bond strength index IBSI) to probe and compare selected covalent bond strength in key intermediates along the reaction path. ${ }^{33,34}$ The corner stone of the IGM- $\delta g$ approach is the electron density (ED). In this study, using the IGMPlot code, both covalent and non-covalent interactions were quantified with ED derived from a wave function (DFT M06-2X/6-311++G**). In practice, the resulting $\delta g$ isosurfaces representing the interaction regions are colored according to the ED value oriented with the sign of $\lambda_{2}$ (second eigenvalue of the ED Hessian). A BGR colour code is then used: red for strongly repulsive, green for van der Waals, and blue for strongly attractive interactions. An attractive feature of the IGM approach is to extract the interaction signature of user-selected fragments ( $\delta g^{\text {inter }}$ descriptor). This fragments methodology was here applied in order to focus our attention on the noncovalent interaction between the oxindole and phenyl moieties. This way, plotting $\delta g^{\text {inter }}$ isosurfaces in real space provides us with a visual understanding of the non-covalent forces only between these two fragments. When the two fragments reduce to an atom pair, the resulting $\delta g^{\text {pair }}$ descriptor allows probing a selected covalent bond. In addition to identifying the interactions, the $\delta g$ signature can be integrated to quantify the electron sharing interaction. 


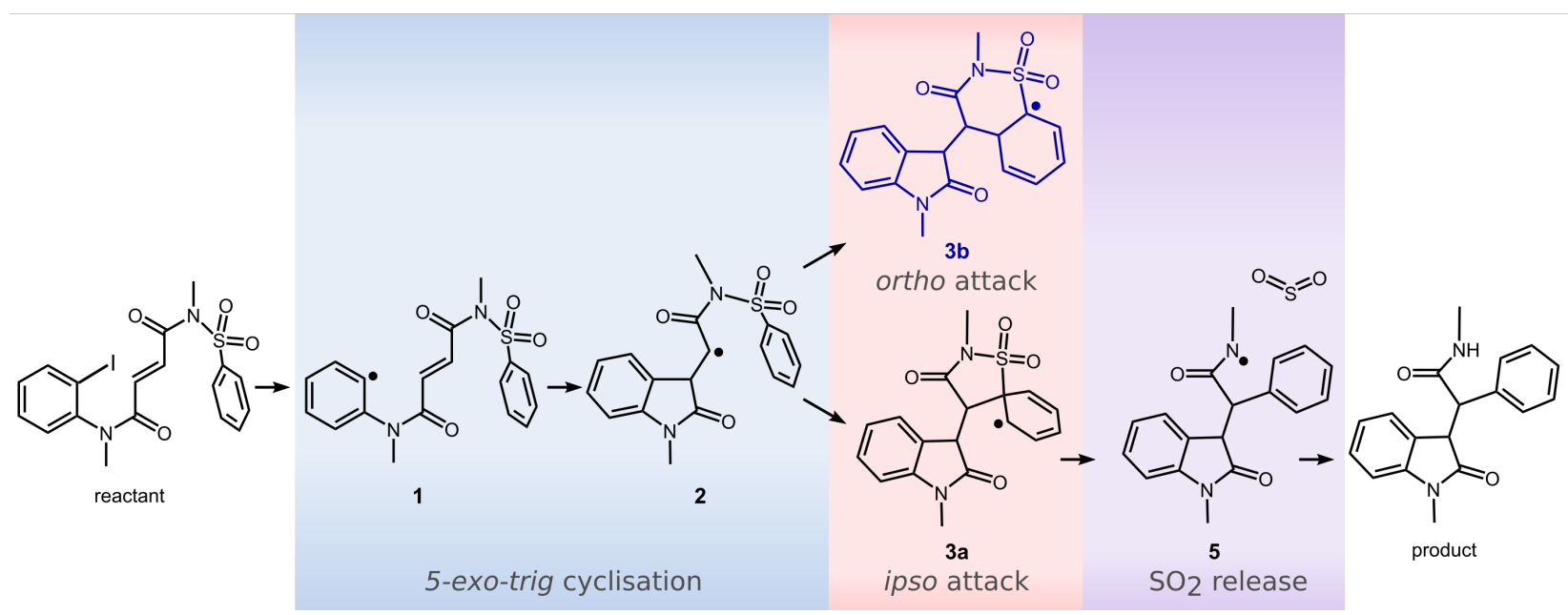

Scheme 2. Reaction scheme of the radical cyclisation-Smiles rearrangement.

This integration scheme has successfully been employed to address non-covalent binding energy in a ligand-target study. ${ }^{35}$ Here, we used this approach at the quantum mechanical level of theory to assess the $\pi$-stacking between the oxindole and phenyl moieties along the reaction path. The electron sharing score $\left(\Delta g^{\text {inter }}\right)$ was obtained by summing the local $\delta g \times d v$ quantities over the whole grid (where $d v$ is an elementary volume). In other respects, to estimate the strength of selected covalent bonds, the IGM-IBSI integration scheme was applied. ${ }^{23}$ Figures displaying isosurfaces and structural parameters were made using the software packages Visual Molecular Dynamics (VMD) ${ }^{36}$ and Chemcraft. ${ }^{37}$ The complementary spin density distribution analysis was performed by using the Chemissian code $^{38}$ and is reported in ESI.

A conformational search procedure has been carried out to explore the structure ensemble of some species along the reaction path. Thus, starting from DFT minimized structures, conformational minima were found by using the CREST tool coupled to the semi-empirical tight-binding based quantum chemistry method GFN2-xTB. ${ }^{39,40}$ The Boltzmann populations were then derived at $447 \mathrm{~K}$. A special treatment has been set for species 1 ( $N^{1}$-(2-ylophenyl)- $N^{1}, N^{4}$-dimethyl- $N^{4}$ (phenylsulfonyl)fumaramide) because this radical is extremely reactive and immediately converts to species $\mathbf{2}(\mathrm{N}$-methyl-2-(1methyl-2-oxoindolin-3-yl)- $N$-(phenylsulfonyl-1-yl)-2-

acetamidyl) during the conformational sampling. That is the reason why its reduced form was considered instead.

Quantum mechanical molecular dynamics (QM/MD) were performed on radical species 1 (doublet state) with GFN2XTB. ${ }^{39,40}$ At first, the energy of the entire system was minimized to avoid instabilities during the MD. A suitable procedure for heating and equilibrating the system is used by the program $x t b$. Trajectories were produced in the non-polar solvent $n$-hexane at $447 \mathrm{~K}$ to approach experimental conditions by applying the implicit solvent model GBSA. ${ }^{41}$ Coordinates of the system were written every $5 \mathrm{fs}$. To get a more representative statistical sample, starting from different conformations (taken from the
CREST sampling), ten $50 \mathrm{ps}$ trajectories have been produced in parallel.

\section{Results and Discussion}

Before presenting the results, we have to recall some experimental key elements which are summarised in Scheme 2. Firstly, the reaction is experimentally triggered by a radical initiator, which abstracts the iodine atom of the reactant. Thereafter, experimental rationalization suggests that a first intramolecular cyclization takes place, assuming that a radical intermediate is produced. Then, a Smiles rearrangement is assumed to occur from the radical intermediate through an ipso attack involving the carbon atom attached to the $\mathrm{SO}_{2}$ group. In that scenario, an $\mathrm{SO}_{2}$ release, involving two bond cleavages, is deemed to arise in the final stage leading to the final product, the reduced form of the amidyl radical. However, some questions remain about the exact mechanism, such as the identity of the rate-determining step (Smiles rearrangement or $\mathrm{SO}_{2}$ release). Additionally, one may wonder if this particular Smiles rearrangement involves a one-step concerted mechanism, i.e., an intramolecular radical aromatic substitution on carbon $\mathrm{C}_{\text {ipso }}$ (Scheme 1) with a simultaneous S-C homolytic bond cleavage; or if it involves a cyclic five-membered intermediate generated by a 5-exo-trig ring closure. On the other hand, an alternatively 6-endo-trig ring closure involving a radical attack on carbon $\mathrm{C}_{\text {ortho }}$ is not precluded by the Baldwin rules ${ }^{42,43}$ but does not occur experimentally. Finally, concerning the $\mathrm{SO}_{2}$ release, the possibility of a concerted N-S and S-C bonds cleavage should be clarified.

Theoretical chemistry offers several ways to investigate these points and to gain insight into this reaction mechanism. This study is presented in three main sections: i) a detailed analysis of the energy profile determined for two competing pathways, ii) an alternative route exploration, and iii) an IGM study of the role of a specific intramolecular $\pi-\pi$ stacking interaction. Additionally, a spin distribution analysis has been conducted along the reaction path (see the ESI). 


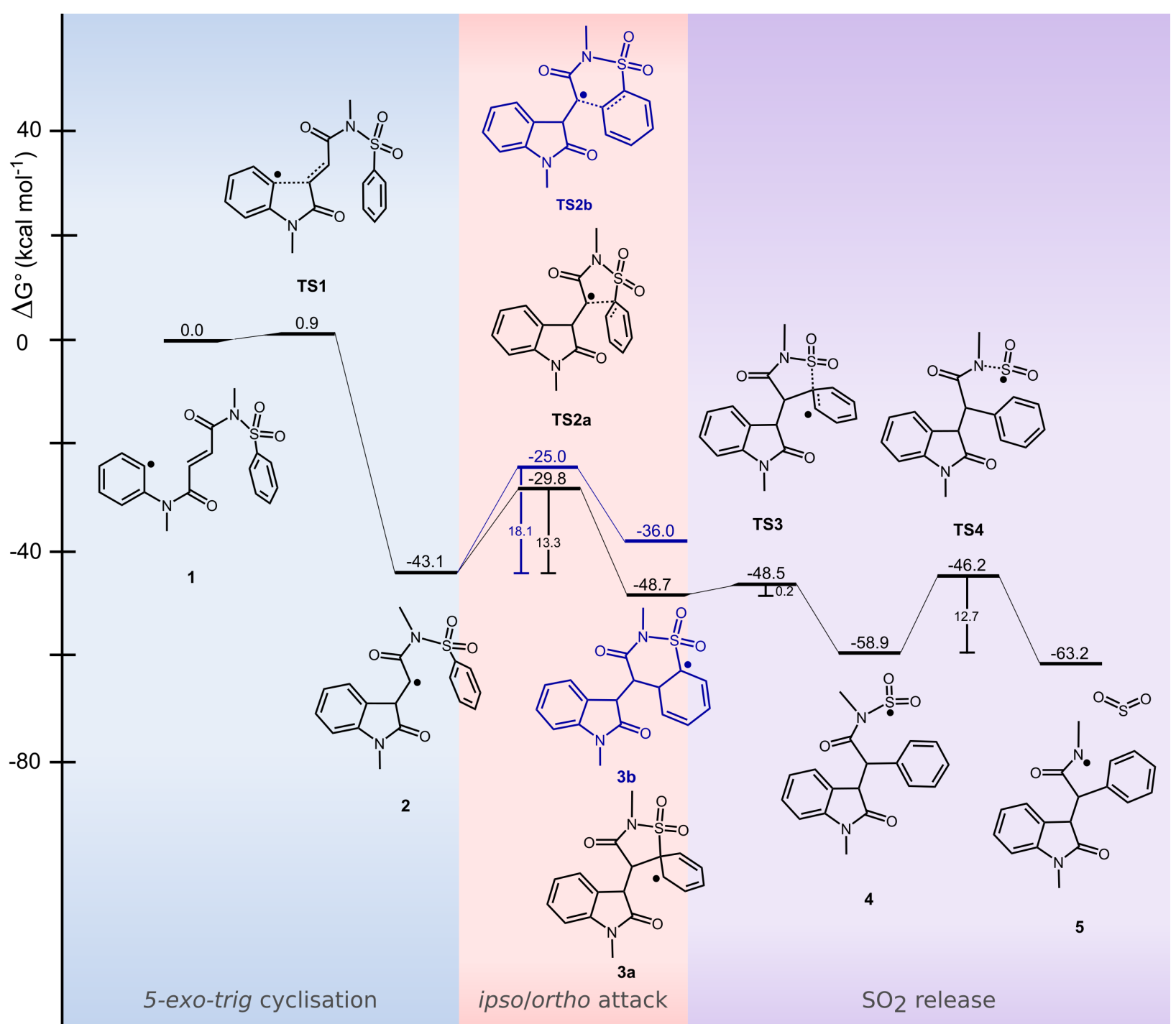

Figure 1. Standard Gibbs free energy $\left(\Delta \mathrm{G}^{\circ}\right)$ profile calculated at $447 \mathrm{~K}$ for the radical cascade. DFT M06-2X/6-311++G** considering $n$-decane as solvent (PCM).

\section{Energy profile}

The calculated energetic profile of the domino radical cyclisation-Smiles rearrangement combination at $447 \mathrm{~K}$ and considering the $n$-decane as solvent (as in the experimental conditions) is presented in Figure 1.

The calculated reaction pathway starts with the 5-exo-trig cyclisation of radical 1 through a very low free energy barrier of $0.9 \mathrm{kcal} \mathrm{mol}^{-1}$ (TS1) resulting in the formation of an oxindole group in 2. From experiments, after the domino reaction occurs, there is no remaining reactant $\mathbf{1}$. Therefore, our DFT results, that predict a very low activation free energy and a large exothermicity $\left(\Delta \mathrm{H}^{\circ}{ }_{447 \mathrm{~K}}=-48.1 \mathrm{kcal} \mathrm{mol}^{-1}\right.$, see Table 1$)$ for this entrance channel, are in good agreement with experimental observations, endorsing the DFT level of theory herein considered. We have also assessed the reaction rate at $447 \mathrm{~K}$ by means of ten independent MD simulations carried out at the QM level of theory (see computational details). The radical cyclisation takes place extremely rapidly, in the range 0.7-19 ps. Due to the quantum level of theory used (GFN2-xTB), these MD simulations give only an estimate of the reaction rate, but clearly emphasize the low barrier of this initial step.

From radical intermediate $\mathbf{2}$, two competing pathways have been explored: the first one involves the intermediate $\mathbf{2}$ undergoing a five-membered cyclisation via an ipso attack (TS2a, $\Delta \mathrm{G}^{\circ}=13.3 \mathrm{kcal} \mathrm{mol}^{-1}$ ), the second pathway considers a six-membered cyclisation via an attack of the phenyl ortho position (TS2b, $\Delta \mathrm{G}^{\circ \neq}=18.1 \mathrm{kcal} \mathrm{mol}^{-1}$ ). Indeed, the occurrence of a competition between an ipso attack (leading to the Smiles rearrangement) and the direct ortho addition has previously been demonstrated experimentally for some sulfonyl radicals (including sulfonamide derivatives). ${ }^{10}$ From our calculations, although forming a strained 5-membered ring in TS2a, the ipso attack is predicted to be kinetically preferred over the 6membered cyclic ortho attack involving TS2 b, by $4.8 \mathrm{kcal} \mathrm{mol}^{-1}$. This is surprising since a more strained structure is revealed in the five-membered ring generated by the ipso approach in comparison to the six-membered ring (see Figure 2, CNS angles of $117^{\circ}$ and $122^{\circ}$ in TS2a and TS2b, respectively). 


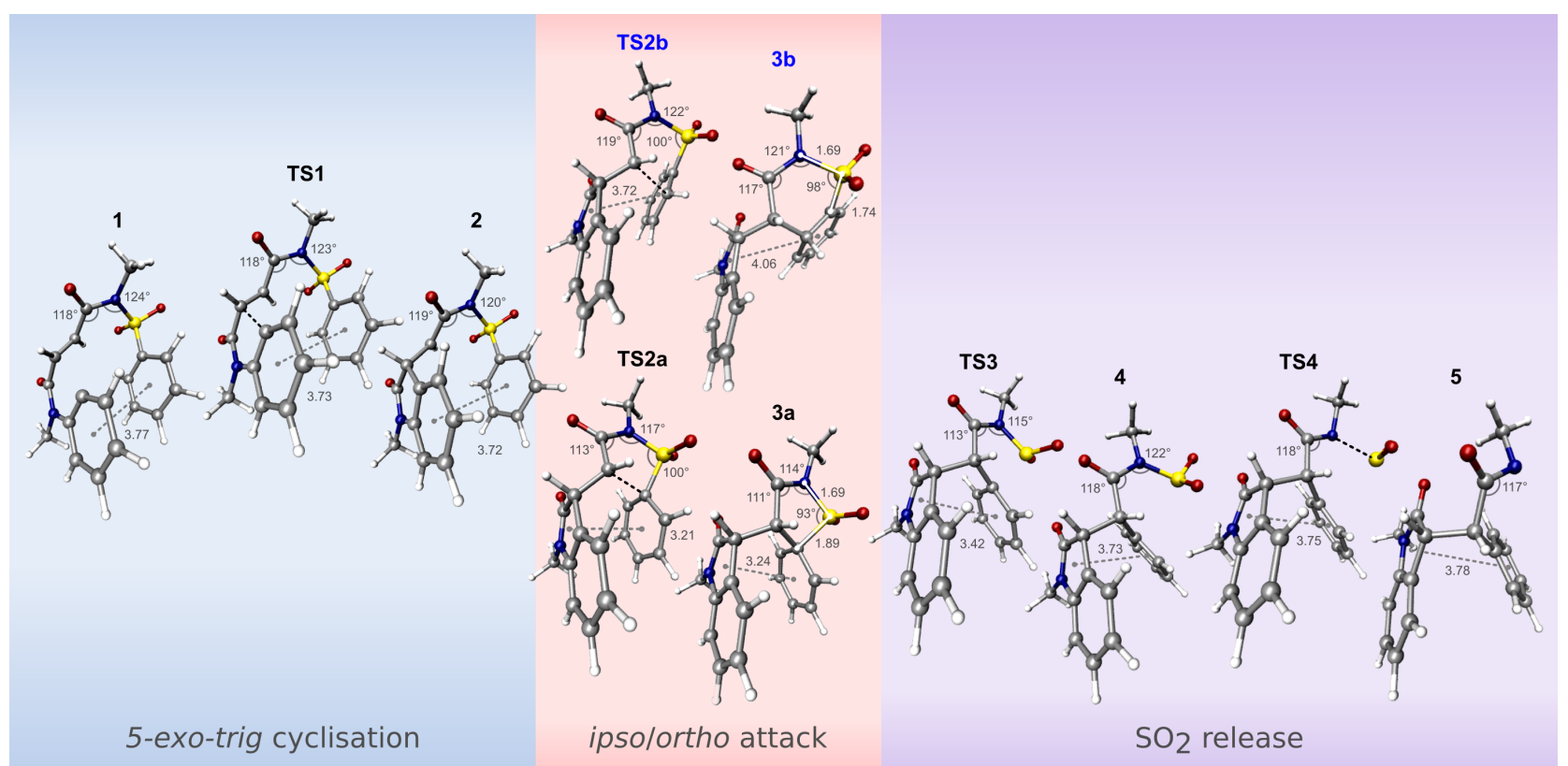

Figure 2. Optimized structures and relevant structural parameters of the species involved in the radical cascade (bond distances and angles in Angströms and degrees, respectively). DFT M06-2X/6-311++G** considering $n$-decane as solvent (PCM).

Table 1. Energies for the species involved in the radical cascade at $447 \mathrm{~K}$, and $\Delta g(\pi-\pi)$ score. DFT(M06-2X)/6-311++G** considering $n$-decane as solvent (PCM).

\begin{tabular}{|cccccccccccc|}
\hline & $\mathbf{1}$ & TS1 & $\mathbf{2}$ & TS2a & TS2b & 3a & 3b & TS3 & $\mathbf{4}$ & TS4 & $\mathbf{5}$ \\
\hline $\begin{array}{c}\Delta \mathrm{G}^{\circ} \\
\left(\mathrm{kcal} \mathrm{mol}^{-1}\right)\end{array}$ & 0.0 & -0.9 & -43.1 & -29.8 & -25.0 & -48.7 & -36.0 & -48.5 & -58.9 & -46.2 & -63.2 \\
$\begin{array}{c}\Delta \mathrm{H}^{\circ} 447 \mathrm{~K} \\
\left(\mathrm{kcal} \mathrm{mol}^{-1}\right)\end{array}$ & 0.0 & -0.9 & -48.1 & -34.2 & -28.7 & -52.1 & -42.0 & -51.4 & -58.8 & -46.0 & -45.5 \\
$\begin{array}{c}\Delta \mathrm{S}^{\circ} \\
\left(\mathrm{cal} \mathrm{K} \mathrm{mol}^{-1}\right)\end{array}$ & 0.0 & -3.9 & -11.1 & -9.8 & -8.3 & -3.6 & -13.4 & 4.7 & 0.3 & 0.4 & 39.7 \\
$\Delta g(\pi-\pi)$ (a.u.) & 0.47 & 0.45 & 0.43 & 0.70 & 0.57 & 0.69 & 0.51 & 0.61 & 0.47 & 0.46 & 0.49 \\
\hline
\end{tabular}

The IGM analysis (Figure 3) clarifies the preference for the ipso attack (TS2a) over the ortho addition (TS2b). Actually, TS2a features a wider $\delta g^{\text {inter }}$ isosurface highlighting a larger intramolecular $\pi$-stacking between the oxindole and phenyl moieties, and to quantify this particular interaction, the local $\delta g^{\text {inter }}(\pi-\pi)$ descriptor has been integrated leading to the interaction score $\Delta g^{\text {inter }}(\pi-\pi)$. The larger value obtained for TS2a $\left(\Delta g^{\text {inter }}(\pi-\pi)=0.70\right.$ a.u. $)$ in comparison with TS2b $\left(\Delta g^{\text {inter }}(\pi-\pi)=0.57\right.$ a.u. $)$ confirms a more intense non-covalent interaction in the former case. This is also in line with the shorter distance observed between the aromatic rings ( $3.21 \AA$ in TS2a vs. $3.72 \AA$ in TS2b, see Figure 2), thus promoting the rise of van der Waals interactions. Afterwards, the transition state TS2a evolves towards the five-membered radical 3a at the cost of the ring aromaticity loss (the phenyl group turns into a cyclohexadienyl radical). The alternative channel TS2b (ortho attack), which also causes the loss of the ring aromaticity, leads to the product $\mathbf{3 b}$, much less stable than $3 \mathbf{a}$ by $12.7 \mathrm{kcal}^{\mathrm{mol}} \mathrm{m}^{-1}$. This result is in line with experimental data indicating exclusive isolation of the ipso-final addition reduced product. ${ }^{17}$ Surprisingly, 2 experiences an entropy penalty upon forming the 6-membered fused bicyclic compound $\mathbf{3 b}$ (ortho attack, $\Delta \mathrm{S}^{\circ}=$ $-2.3 \mathrm{cal} \mathrm{mol}^{-1} \mathrm{~K}^{-1}$ ) compared to the 5 -membered spirocyclic compound 3a (ipso attack, $\Delta \mathrm{S}^{\circ}=7.5 \mathrm{cal} \mathrm{mol}^{-1} \mathrm{~K}^{-1}$ ). Thus, unlike the entropy conventional view, forming a 5 -membered ring is not detrimental in this case. This is very likely due to the different junction modes involved here: spiro (3a) vs. fused (3b). This entropic difference is substantially enhanced by the exothermicity of the pathway $\mathbf{2} \rightarrow 3 \mathrm{a}: \Delta \mathrm{H}^{\circ}{ }_{447 \mathrm{~K}}=-4.0 \mathrm{kcal} \mathrm{mol}^{-1}$ in comparison with the endothermic route $\mathbf{2} \rightarrow \mathbf{3 b}: \Delta \mathrm{H}_{447 \mathrm{~K}}=6.1$ $\mathrm{kcal} \mathrm{mol}^{-1}$. Part of this enthalpy difference stems from the specific configuration of the phenyl group facing the oxindole moiety in the entrance channel of the Smiles rearrangement. This specific non-covalent interaction (discussed below) causes a growing attractive $\pi$-stacking as measured by $\Delta g^{\text {inter }}(\pi-\pi)$ : 0.43 a.u. in $\mathbf{2} \rightarrow 0.69$ a.u. in $\mathbf{3 a}$ (see Figure 3 ). In comparison, the other channel (ortho attack) leads to a lower stabilizing interaction in $\mathbf{3 b}: \Delta g^{\text {inter }}(\pi-\pi)=0.51$ a.u. 


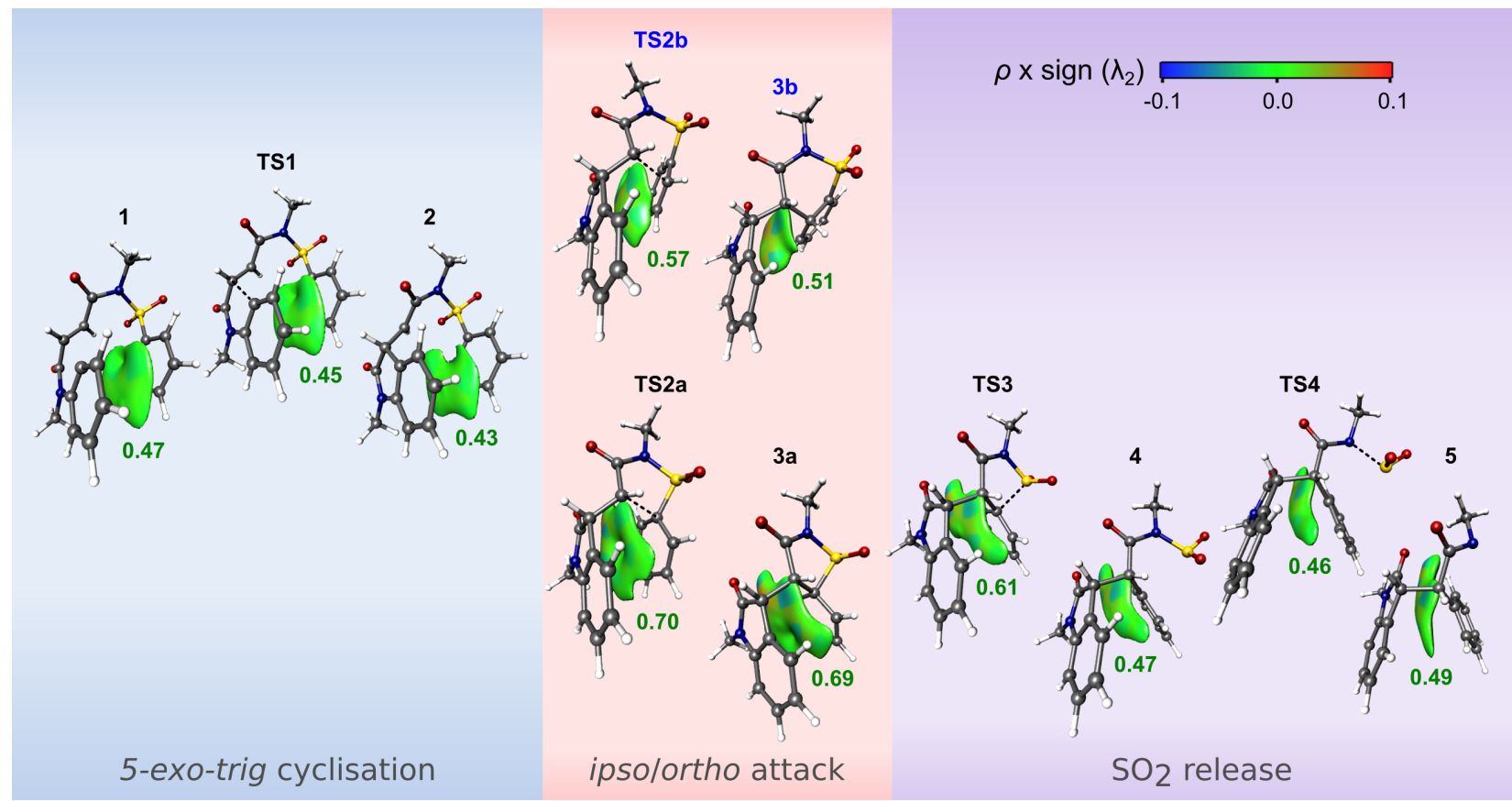

Figure 3. IGM- $\delta g$ quantum analysis (DFT M06-2X/6-311++G**) for the $\pi-\pi$-stacking interaction between the oxindole and phenyl moieties along the reaction; $\delta g^{\text {inter }}(\pi-\pi)=0.012$ a.u. isosurfaces; color coding in the range -0.1 a.u. $<\rho \times \operatorname{sign}\left(\lambda_{2}\right)<0.1$ a.u); the integrated value of $\delta g^{\text {inter }}(\Delta g(\pi-\pi))$ is reported in a.u.

The rate constant $k$ for each elementary reaction $\left(k_{2 a}\right.$ for 2 $\rightarrow$ TS2a $\rightarrow$ 3a and $\mathrm{k}_{2 \mathrm{~b}}$ for $\mathbf{2} \rightarrow \mathrm{TS} 2 \mathrm{~b} \rightarrow \mathbf{3 b}$ ) has been calculated by using the transition state theory at $298 \mathrm{~K}$ and $447 \mathrm{~K}$, employing the KiSThelP program. ${ }^{32}$ The resulting branching ratio $\Gamma$ has been calculated according to the following expression: $\Gamma_{2 i}=k_{2 i} /\left(k_{2 a}+k_{2 b}\right)$. For the Smiles rearrangement pathway, although slightly decreasing as a function of the temperature in the range $298-447 \mathrm{~K}, \Gamma_{2 a}$ still represents about $97 \%$ of the total reaction at $447 \mathrm{~K}$. From all these theoretical results, the Smiles rearrangement entrance channel (TS2a) is expected to dominate the reaction.

From 4, in order to arrive at the amidyl rearrangement product 5 (prefiguring the experimentally observed final reduced compound), the departure of the $\mathrm{SO}_{2}$ moiety must now be studied. According to other authors, ${ }^{44}$ this $\mathrm{SO}_{2}$ release from $\mathrm{N}$ amidosulfonyl radical intermediate could be considered as the limiting step of the Smiles rearrangement, what is not the case for the radical cascade studied here, as demonstrated hereafter. To initiate this last stage, the radical 3a, exhibiting a relatively small $\mathrm{N}-\mathrm{S}-\mathrm{C}$ angle of $93^{\circ}$, experiences a S-C cleavage (see Figure 2). This step involves the liberation of the fivemembered ring strain, that is clearly a major driving force. In addition, this dissociative step is concomitant with the regeneration of the phenyl ring aromaticity via TS3 in an almost barrierless step $\left(\Delta G^{\circ \ddagger}=0.2 \mathrm{kcal} \mathrm{mol}^{-1}\right)$ to afford the sulfonamide radical $4\left(\Delta \mathrm{G}^{\circ}=-58.9 \mathrm{kcal} \mathrm{mol}^{-1}\right)$. Despite the pronounced structural rearrangement caused by the S-C cleavage, such a ring rearomatization gives rise to a high stabilization of $\mathbf{4}$ with respect to the previous intermediate $3 \mathbf{a}\left(10.2 \mathrm{kcal} \mathrm{mol}^{-1}\right)$.
From a geometrical point of view, this bond breaking is detrimental to the aforementioned $\pi$-stacking, with a $3.73 \AA$ distance between the aromatic fragments in $\mathbf{4}$ (see Figure 2). This lowering of intramolecular non-covalent interaction is markedly unveiled in Figure 3 by the IGM $\pi-\pi$ isosurfaces that contract along the reaction pathway $3 \mathrm{a} \rightarrow \mathrm{TS} 3 \rightarrow 4$, and it is quantitatively confirmed by the associated decreasing score $\Delta g(\pi-\pi): 0.69,0.61$ and 0.47 a.u., for $3 \mathbf{a}$, TS3 and 4 , respectively. As a final step of the Smiles cascade reaction, the $\mathrm{SO}_{2}$ is released via TS4 $\left(\Delta \mathrm{G}^{\circ \neq}=12.7 \mathrm{kcal}^{\circ} \mathrm{mol}^{-1}\right)$ evolving towards the $N$-amino radical $5\left(\Delta \mathrm{G}^{\circ}=-63.2 \mathrm{kcal} \mathrm{mol}^{-1}\right)$ after the $\mathrm{N}-\mathrm{S}$ bond rupture, with almost no significant structural variations with respect to 4 (except for the liberated $\mathrm{SO}_{2}$ ). The $\mathrm{SO}_{2}$ departure during the oxidation of sulfonamides containing five- and six-membered heterocyclic moieties has been recently reported $^{19}$ and supported by DFT calculations at the same level of theory than in our study, with an energetic barrier of $17.6 \mathrm{kcal} \mathrm{mol}^{-1}$, in line with our results $\left(\Delta \mathrm{H}_{447 \mathrm{~K}}=12.8 \mathrm{kcal} \mathrm{mol}^{-1}\right)$. However, in this reference, the $\mathrm{SO}_{2}$ release arises in a one-step concerted mechanism while a two-step mechanism has first been considered in our work.

Starting from intermediate $\mathbf{3 a}$, we have also explored the possibility of a concerted mechanism, i.e. a simultaneous $\mathrm{N}-\mathrm{S}$ and $\mathrm{S}-\mathrm{C}$ cleavage, even if there is no experimental evidence of this process in this particular case. Hence, a two-dimensional energy scan has been carried out by varying the two distances $\mathrm{N}-\mathrm{S}$ and S-C. Vibrational frequency calculations have been performed at each point of this scan in order to detect structures with the appropriate imaginary normal mode corresponding to such a concerted extrusion mechanism. 


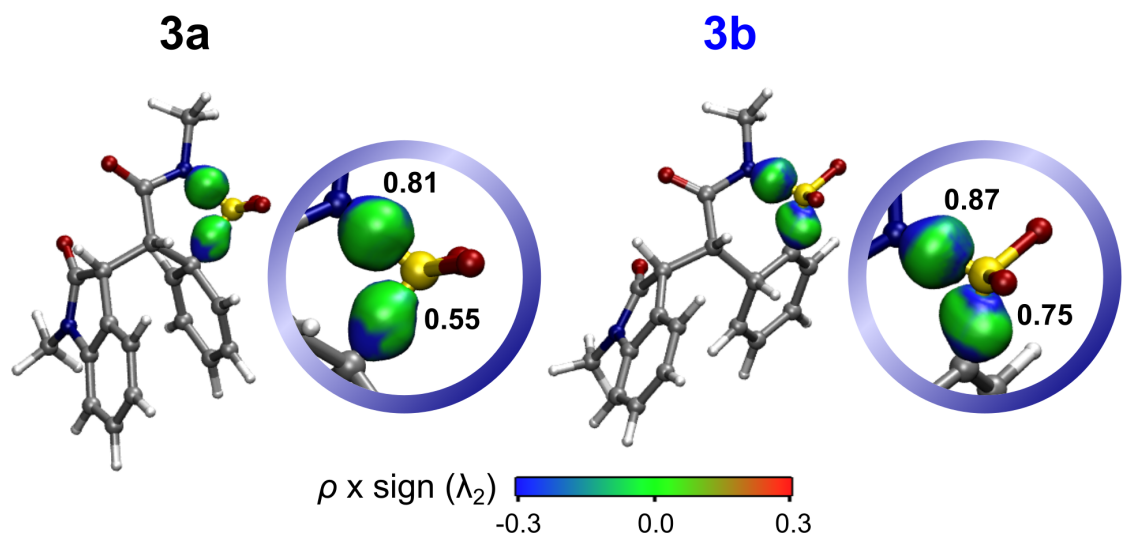

Figure 4. IGMPLOT quantum analysis (DFT M06-2X/6-311++G**) for the $\mathrm{N}-\mathrm{S}$ and $\mathrm{S}-\mathrm{C}$ bonds of intermediates $\mathbf{3 a}$ and $\mathbf{3 b}\left(\delta g^{\text {intra }}=\right.$ 0.6 a.u. isosurfaces; color coding in the electronic density range -0.3 a.u. $<\rho \times \operatorname{sign}\left(\lambda_{2}\right)<0.3$ a.u).

Subsequent transition state optimizations always led to the already found TS4, thus supporting the above discussed twostep $\mathrm{SO}_{2}$ release.

In summary, the free energy profiles predicted at $447 \mathrm{~K}$ discloses intermediates and products more stable than the radical reactant $\mathbf{1}$. More precisely, the molecular system becomes increasingly more stable going along the reaction coordinate. The initial step (the 5-exo-trig cyclization) is almost barrierless and then extremely fast. Moreover, the oxindole product $\mathbf{2}$ is much more stable than the reactant, pointing out an irreversible reaction. This is in very good agreement with the experimental data showing the lack of initial reactant 1 (or derivatives resulting from radical recombination) at the end of the reaction. Following this initial intramolecular cyclization, the attack on the ipso position of the phenyl ring (the entrance channel for the Smiles rearrangement) is preferred to the ortho attack, in line with experimental observations. To a great extent, the Smiles rearrangement channel is promoted by a substantial $\pi$ - $\pi$-stacking interaction between the phenyl and the oxindole moieties. The formation of the intermediate spirocyclic compound 3a through a 5-membered ring cyclization is clearly identified as the rate determining step of the cascade with a free energy barrier height of $13.3 \mathrm{kcal} \mathrm{mol}^{-1}$ at $447 \mathrm{~K}$. The subsequent $\mathrm{SO}_{2}$ release is fast, starting with an almost barrierless $\mathrm{S}-\mathrm{C}$ dissociation. Afterwards the N-S cleavage shifts the equilibrium toward the products, thus favouring the overall process leading to the amidyl radical $\mathbf{5}$.

\section{Alternative reactions}

Although the Smiles rearrangement is the main focus of the present study, competing pathways have also been examined in order to gain a more complete picture of the factors governing the overall mechanism. Actually, experimentally, the presence of tris(trimethylsilyl)silane (TTMSS) as reducing agent in the reaction medium, could in principle result in the reduction of radical species generated from secondary pathways. Thus, in addition to the already examined alternative channel $\mathbf{2} \rightarrow$ TS2 b $\rightarrow \mathbf{3 b}$, complementary pathways starting from intermediate $\mathbf{3 a}$ and $\mathbf{3} \mathbf{b}$ have been examined.

Theoretically, from 3a, the hypothetic alternative N-S cleavage could occur prior to the S-C bond dissociation. However, the IGM bond strength analysis conducted on the bonds N-S (IBSI = $0.81)$ and S-C (IBSI $=0.55)$ of structure $3 a$ (Figure 4$)$ supports the assumption of a preferred $\mathrm{S}-\mathrm{C}$ dissociation occurring in first place. Moreover, the $\mathrm{N}-\mathrm{S}$ cleavage would generate a very unlikely chemical species exhibiting three unpaired electrons on $\mathrm{N}, \mathrm{S}$ and $\mathrm{C}$, and the aromaticity could not be restored as it occurs in pathway $\mathbf{3 a} \rightarrow \mathbf{4}$. For these reasons, the early N-S dissociation in $\mathbf{3} \mathbf{a}$ has been discarded.

In the fused bicyclic intermediate $\mathbf{3 b}$ (the product of the ortho attack), the rearomatization of the cyclohexadienyl fragment would only be achieved through an homolytic ortho-C-H cleavage known to be highly endothermic. That is the reason why this pathway has not been examined here. In other respects, the $\mathbf{3 b} \mathrm{S}-\mathrm{C}$ bond cleavage is assumed to be very unlikely as it cannot restore the aromaticity. Its alternative, the 3b N-S homolytic bond dissociation, would form a $\mathrm{C}=\mathrm{S}$ bond with spin density on nitrogen. Although this mechanism is theoretically conceivable since the ipso carbon in $\mathbf{3} \mathbf{b}$ exhibits a significant spin density $(0.38 \mathrm{e}$, see the spin density distribution analysis in the $\mathrm{ESI}$ ) our calculations show that this represents an endothermic channel $\left(\mathbf{2} \rightarrow \mathbf{3 b}, \Delta \mathrm{G}^{\circ}=7.1 \mathrm{kcal} . \mathrm{mol}^{-1}\right)$. Moreover, the IGM-IBSI analysis (see Figure 4) delivers a bond strength of 0.87 for $\mathrm{N}-\mathrm{S}$ in $\mathbf{3 b}$, significantly larger than the bond strength of 0.55 for S-C in 3a, discarding such an unlikely first N-S cleavage. All these factors explain the lack of $\mathbf{3} \mathbf{b}$ derivative products in experimental results.

\section{Focus on intramolecular $\pi$-stacking}

As pointed out above, the intramolecular $\pi-\pi$ stacking interaction between the oxindole and phenyl moieties seems partly responsible for the more favourable ipso pathway $\mathbf{2} \rightarrow \mathbf{3 a}$ with respect to the ortho-addition channel $\mathbf{2} \rightarrow \mathbf{3 b}$. This effect reaching its maximum between TS2a and 3a (see Figure 3 ). However, one might wonder whether such weak interaction 
holds at experimental (high) temperature. For that purpose, we performed a sampling of the thermally accessible conformers using the CREST facility and the XTB-GFN2 method $^{39,40}$ at $447 \mathrm{~K}$ in a non-polar solvent (see computational details). For species $\mathbf{1}, \mathbf{2}, \mathbf{3 a}$ and $\mathbf{3 b}$, the Boltzmann populations (at $447 \mathrm{~K}$ ) of conformers involving $\pi-\pi$-stacking interaction have been calculated. For species with few degrees of freedom (3a, 3b), the favored conformation features $\pi$-stacking between the oxindole and phenyl moieties. For these $\pi$-stacking conformers, high Boltzmann populations have been obtained at $447 \mathrm{~K}$ for $\mathbf{3 a}$ (47.3\%) and 3b (67.5\%), in contrast to 1 (7.6\%) and 2 (23.6\%) where more conformers are accessible at $447 \mathrm{~K}$ given that $\pi$ stacking is not predominant. Remarkably, our results show that, due to the limited degrees of freedom in cyclic intermediates $\mathbf{3 a}$ and $\mathbf{3 b}$, the $\pi$-stacking between the oxindole and phenyl moieties is still present at $447 \mathrm{~K}$. This specific interaction is expected to play a relevant role in stabilizing the system after the 5-exo-trig cyclisation of 1 . The growing $\pi-\pi$ stacking interaction emphasized by the IGM- $\delta g^{\text {inter }}$ analysis along the $\mathbf{2}$ $\rightarrow$ TS2a $\rightarrow$ 3a pathway stems from the proper face-to-face oxindole-phenyl arrangement. Clearly, only the five-membered ring cyclization occurring during this route enables such a favourable configuration. Removing the $-\mathrm{SO}_{2}$ - linker or lengthening it, will undoubtedly alter the favourable $\pi-\pi$ stacking interaction. This feature will have to be taken into account in further structured-based design studies. In particular, the chain length effect in the functionalization of new sulfonylated derivatives subjected to this radical cascade will have to be carefully examined according to this criterion.

\section{Conclusions}

In this work we have conducted a detailed mechanistic study of the domino radical cyclisation-Smiles rearrangement by applying, in addition to conventional tools for exploring stationary points on the potential energy surface, a set of novel post-processing methodologies based on the IGM- $\delta g$ approach. Our theoretical results have been compared with available experimental data and a very good agreement is observed. This validates the computational tools employed herein, laying the foundations for future works aiming at designing new scaffolds of therapeutic interest derived from this synthetic strategy. From this mechanistic investigation, it turns out that the Smiles rearrangement stage takes place here in two steps rather than in a direct intramolecular radical substitution. The first step is the rate-determining step of the overall reaction, which corresponds to the 5-membered ring closure resulting from the radical attack on the ipso carbon bearing the sulfonyl group. The lower energy barrier found for the ipso attack, compared with the alternative ortho attack route, has been ascribed to the presence of a more intense intramolecular $\pi-\pi$ stacking during the 5-membered ring closure. This results was achieved through the IGM- $\delta g$ analysis. This work highlights the new possibilities offered by the IGM- $\delta g^{\text {inter }}$ approach in properly quantifying the intramolecular non-covalent forces along a reaction at the quantum level of theory.
The final step of the mechanism involving the $\mathrm{SO}_{2}$ release is predicted to occur in two successive steps. It starts with an almost barrierless $\mathrm{S}-\mathrm{C}$ dissociation followed by a $\mathrm{N}-\mathrm{S}$ cleavage in the 5-membered strained spirocyclic compound resulting from the ipso attack, which shifts the equilibrium toward the products, thus favoring the overall process. This sequence of bond cleavages has been clarified by using the bond strength IGM-IBSI score which turns out to be a relevant complementary tool to estimating interactions in the covalent domain. The effectiveness of the IGM-based tools has been successfully tested with this challenging domino radical cyclisation-Smiles rearrangement combination. We are confident that this novel approach will be applied to other challenging reactions, providing support to mechanistic investigations devoted to the optimization of organic process leading to products of therapeutic interest.

\section{Conflicts of interest}

There are no conflicts to declare.

\section{Acknowledgements}

This work was supported by a Grant (L. Doudet, PhD thesis) from the Université de Reims Champagne-Ardenne and the ICMR laboratory (Institut de Chimie Moléculaire de Reims). We thank the MaSCA (Maison de la Simulation de Champagne-Ardenne, France) for various supports including computing facilities (http://romeo.univ-reims.fr) and the CRIANN computational center (http://www.criann.fr) for additional support.

\section{Bibliographic references}

1 Z.-S. Wang, Y.-B. Chen, H.-W. Zhang, Z. Sun, C. Zhu and L.-W. Ye, J. Am. Chem. Soc., 2020, 142, 3636.

2 C. M. Holden and M. F. Greaney, Chem. Eur. J., 2017, 23, 8992.

3 R. Loven and W. N. Speckamp, Tetrahedron Lett., 1972, 13, 1567.

4 J. J. Koehler and W. N. Speckamp, Tetrahedron Lett., 1977, 18, 631.

5 T. J. A. Snape, Chem. Soc. Rev., 2008, 37, 2452.

6 D. M. Whalley, H. A. Duong and M. F. Greaney, Chem. Eur. J., 2019, 25, 1927.

7 A. A. Levy, H. C. Rains and S. Smiles, J. Chem. Soc., 1931, 3264.

8 Z. Wang, Comprehensive Organic Name Reactions and Reagents, John Wiley \& Sons, Hoboken, N. J., USA, 2010.

9 I. Allart-Simon, S. Gérard and J. Sapi, Molecules, 2016, 21, 878.

10 W. B. Motherwell and A. M. K. Pennell, J. Chem. Soc., Chem. Commun., 1991, 877.

11 M. L. E. N. Da Mata, W. B. Motherwell and F. Ujjainwalla, Tetrahedron Lett., 1997, 38, 137.

12 M. L. E. N. Da Mata, W. B. Motherwell and F. Ujjainwalla, Tetrahedron Lett., 1997, 38, 141.

13 J. Xiang, L. Zheng, F. Chen, Q. Dang and X. A. Bai, Org. Lett., 2007, 9, 765.

14 J. Xiang, H. Xie, D. Wen, Q. Dang and X. Bai, J. Org. Chem., 2008, 73, 3281.

15 J. Xiang, L. Zheng, H. Xie, X. Hu, Q. Dang and X. Bai, Tetrahedron, 2008, 64, 9101.

16 E. Brachet, L. Marzo, M. Selkti, B. König and P. Belmont, Chem. Sci., 2016, 7, 5002.

17 M. Pudlo, I. Allart-Simon, B. Tinant, S. Gérard and J. Sapi, Chem. Commun., 2012, 48, 2442. 
18 P. R. Tentscher, S. N. Eustis, K. McNeill and J. S. Arey, Chem. Eur. J., 2013, 19, 11216.

19 M. Feng, J. C. Baum, N. Nesnas, Y. Lee, C.-H. Huang and V. K. Sharma, Environ. Sci. Technol., 2019, 53, 2695.

20 P. Vasko, J. Hurmalainen, A. Mansikkamäki, A. Peuronen, A. Mailman and H. M. Tuononen, Dalton Trans., 2017, 46, 16004.

21 C. Lefebvre, G. Rubez, H. Khartabil, J.-C. Boisson, J. ContrerasGarcía and E. Hénon, Phys. Chem. Chem. Phys., 2017, 19, 17928.

22 C. Lefebvre, H. Khartabil, J.-C. Boisson, J. Contreras-García, J.P. Piquemal and E. Hénon, ChemPhysChem, 2018, 19, 724.

23 J. Klein, H. Khartabil, J.-C. Boisson, J. Contreras-García, J.-P. Piquemal and E. Hénon, J. Phys. Chem. A, 2020, 124, 1850.

24 D. L. Hughes, U.-H. Dolling, K. M. Ryan, E. F. Schoenewaldt and E. J. J. Grabowski. J. Org. Chem., 1987, 52, 4745.

25 L. Ma, P. Jiao, Q. Zhang, D.-M. Du, J. Xu. Tetrahedron: Asymmetry, 2007, 18, 878.

26 Gaussian 16, Revision C.01, M. J. Frisch, G. W. Trucks, H. B. Schlegel, G. E. Scuseria, M. A. Robb, J. R. Cheeseman, G. Scalmani, V. Barone, G. A. Petersson, H. Nakatsuji, X. Li, M. Caricato, A. V. Marenich, J. Bloino, B. G. Janesko, R. Gomperts, B. Mennucci, H. P. Hratchian, J. V. Ortiz, A. F. Izmaylov, J. L. Sonnenberg, D. Williams-Young, F. Ding, F. Lipparini, F. Egidi, J. Goings, B. Peng, A. Petrone, T. Henderson, D. Ranasinghe, V. G. Zakrzewski, J. Gao, N. Rega, G. Zheng, W. Liang, M. Hada, M. Ehara, K. Toyota, R. Fukuda, J. Hasegawa, M. Ishida, T. Nakajima, Y. Honda, O. Kitao, H. Nakai, T. Vreven, K. Throssell, J. A. Montgomery, Jr., J. E. Peralta, F. Ogliaro, M. J. Bearpark, J. J. Heyd, E. N. Brothers, K. N. Kudin, V. N. Staroverov, T. A Keith, R. Kobayashi, J. Normand, K. Raghavachari, A. P. Rendell, J. C. Burant, S. S. Iyengar, J. Tomasi, M. Cossi, J. M. Millam, M. Klene, C. Adamo, R. Cammi, J. W. Ochterski, R. L. Martin, K. Morokuma, O. Farkas, J. B. Foresman and D. J. Fox, Gaussian, Inc., Wallingford CT, 2016.

27 J. Tomasi, B. Mennucci and R. Cammi, Chem. Rev. 2005, 105, 2999.

28 B. Mennucci, J. Tomasi, R. Cammi, J. R. Cheeseman, M. J. Frisch, F. J. Devlin, S. Gabriel and P. J. Stephens, J. Phys. Chem. A, 2002, 106, 6102.

29 S. Miertuš, J. Scrocco and J. Tomasi, Chem. Phys., 1981, 55, 117.

30 M. Cossi, G. Scalmani, N. Rega and V. Barone, J. Chem. Phys., 2002, 117, 43.

31 G. Scalmani and M. J. Frisch, J. Chem. Phys., 2010, 132, 114110.

32 S. Canneaux, F. Bohr and E. Henon, J. Comput. Chem., 2014, $35,82$.

33 J. Klein, E. Pluot, G. Rubez, J.-C. Boisson and E. Hénon, IGMPLOT. Identifying and Characterizing Interactions in Molecules, Reims, France. http://igmplot.univ-reims.fr.

34 G. Frenking and S. Shaik, The Chemical Bond I. Fundamental Aspects of Chemical Bonding. Wiley- $\mathrm{VCH}$, Weinheim, Germany, 2014.

35 H. Huang, H. Liu, H. Zhou, Z. Liang, D. Song, Y. Zhang, W. Huang, X. Zhao, B. Wu, G. Ye and Y. Huang., Drug Des. Dev. Ther. 2019, 13

36 W. Humphrey, A. Dalke and K. J. Schulten, Molec. Graph., 1996, 14, 33.

37 D. A. Zhurko and G. A. Zhurko, ChemCraft 1.6, Plimus, San Diego, CA, EEUU. http://www.chemcraftprog.com.

38 L. V. Skripnikov, Chemissian Version 4.43, Visualization Computer Program. www.chemissian.com.

39 S. Grimme, C. Bannwarth and P. A. Shushkov, J. Chem. Theory Comput., 2017, 13, 1989.

40 C. Bannwarth, S. Ehlert and S. Grimme, J. Chem. Theory Comput., 2019, 15, 1652.

41 R. D. Taylor, P. J. Jewsbury and J. W. Essex, J. Comp. Chem., 2003, 24, 1637.
42 J. E. Baldwin, J. Chem. Soc., Chem. Commun., 1976, 18, 734.

43 J. E. Baldwin, J. Cutting, W. Dupont, L. Kruse, L. Silberman and R. C. Thomas, J. Chem. Soc., Chem. Commun., 1976, 18, 736.

44 C. Moutrille and S. Z. Zard, Chem. Commun., 2004, 1848. 